\title{
SISTEMA GLUTATION-S-TRANSFERASE COMO FATOR PROGNÓSTICO NO CARCINOMA PAPILÍFERO DA TIREOIDE
}

\author{
*Antonio Jose Gonçalves ${ }^{1}$, Osmar Monte ${ }^{2}$, Eliane Cristina Morari ${ }^{3}$, Laura Sterian Ward ${ }^{4}$, Diana Shimoda Nakasako ${ }^{5}$, Juliana Nieto ${ }^{5}$, Marianne Yumi Nakal ${ }^{5}$ \\ Trabalho elaborado no Departamento de Cirurgia da Faculdade de Medicina da Irmandade Santa Casa de Misericórdia de São Paulo Laboratório de Genética \\ Molecular do Câncer (GEMOCA) - UNICAMP, Campinas, SP
}

\author{
*Correspondência: \\ Rua Treze de Maio, 1856, \\ $4^{\circ}$ andar - Bela Vista \\ São Paulo (SP) - Brasil \\ CEP 01327-002 \\ Tel. (+55 11) 3141-3310 \\ Fax. (+55 11) 3289-8813 \\ dr.goncalves@uol.com.br \\ cabpesc@santacasasp.org.br \\ http://santacasasp.org.br/cabpesc
}

\begin{abstract}
RESUMO
ОвJETIvo. Analisar se existe relação entre os fatores moleculares dos genes GTS e a mortalidade dos pacientes com câncer de tireoide dado pelo índice AMES de prognóstico clínico.

MÉtodos. Foram coletadas amostras da tireoide de 66 pacientes com carcinoma papilífero (53 mulheres e 13 homens), de modo a permitir extração do material genético das enzimas. Foram constituídos dois grupos, segundo os fatores prognósticos clínicos de alto e baixo risco, de acordo a classificação AMES. Cada grupo foi avaliado pela presença ou não do genótipo nulo para as enzimas estudadas, correlacionando-os com os fatores prognósticos clínicos (AMES).

Resultados. Foram analisados os resultados de 17 doentes com alto risco (grupo A) e 49 com baixo (grupo B). Todas combinações de genótipos do GSTT1 e GSTM1 foram encontrados. 0 genótipo nulo dos dois genes do grupo de alto risco foi encontrado em 5,8\% e no de baixo risco em $6,1 \%$.

ConcLusão. A presença ou deleção dos genes GST (GSTT1 e GSTM1) não são bom fatores prognósticos no câncer papilífero da tireoide.
\end{abstract}

UnITERMOS: Sistema glutation-S-transferase. Carcinoma bem diferenciado da tireoide. Fatores prognósticos. Sistema AMES.

\section{INTRODUÇÃO}

O câncer de tireoide apresenta uma evolução clínica indolente, apesar de seu prognóstico geralmente favorável (em 90\% dos pacientes a sobrevida está acima dos 10 anos), os fatores que determinam sua evolução ainda são controversos $^{1-3}$. Há tempos existe grande interesse em se definir com precisão quais fatores conseguem prever o risco de mortalidade dessa doença. O tipo histológico, o grau de diferenciação histológica, a idade do paciente na época do diagnóstico, a extensão do tumor e, mais recentemente, os estudos da biologia molecular desses tumores são dados relevantes na determinação do prognóstico e, consequentemente do melhor tratamento para esta doença.

O índice AMES foi criado em 1998 por Cady e Rossi, na Clínica Lahey. Tem como fundamento a análise multifatorial dos fatores prognósticos do câncer de tireoide. Seu nome deriva das iniciais, na língua inglesa, dos quatro fatores avaliados: idade (Age), presença de metástase à distância (Metastasis), extravasamento capsular (Extent) e tamanho do tumor primário
(Size). Os pacientes são divididos em dois grupos, de acordo com o risco de mortalidade: alto e baixo risco ${ }^{4}$.

Os compostos eletrofílicos, tanto endógenos como exógenos, estão constantemente em contato com nossas células e são agentes potencialmente mutagênicos por reagirem sobre a cadeia de DNA provocando modificação de sua estrutura. As enzimas do Glutation-S-Transferase têm um importante papel na carcinogênese dos tumores humanos porque estão envolvidas na neutralização e detoxificação de uma variedade desses compostos, tanto derivados do próprio metabolismo celular, como de substâncias produzidas por indústrias químicas, incluindo metileno clorídrico, etileno, brometo de etídeo, óxido etileno, e 1,3-butadieno-8. Atualmente seis classes de GST's são conhecidas: alpha, mu, pi, theta, omega e zeta ${ }^{1}$.

A carcinogênese do câncer de tireoide ainda é incerta. A exposição à radiação ionizante, principalmente durante a infância é um dos poucos fatores comprovadamente relacionados com a mutação primária, no entanto a deficiência de iodo também tem sido apontada como um fator predisponente para que essa mutação ocorra9-11. Todos esses fatores promovem uma condição

\footnotetext{
1. Professor Adjunto - Chefe da Disciplina de Cirurgia de Cabeça e Pescoço do Departamento de Cirurgia da Faculdade de Ciências Médicas da Santa Casa de São Paulo, São Paulo, SP

2. Professor Adjunto de Clínica Médica da Faculdade de Ciências Médicas da Santa Casa de São Paulo, São Paulo, SP

3. Bióloga da Universidade Estadual de Campinas - UNICAMP, Campinas, SP

4. Professora Adjunta livre docência da Universidade Estadual de Campinas - UNICAMP, Campinas, SP

5. Acadêmicos de Medicina da Faculdade de Ciências Médicas da Santa Casa de São Paulo, São Paulo, SP
} 
de estresse celular, o que estimula a produção de substâncias mutagênicas para a célula tireoidiana. O GST tem papel protetor para o desenvolvimento desse tumor, ajudando a neutralizar a ação mutagênica dessas substâncias. As classes mu e theta são de particular importância no carcinoma de tireoide. A ausência dos genes GSTT1 e GSTM1 (codificadores das classes theta e mu respectivamente) está relacionada com o aumento do risco de desenvolver carcinomas de pulmão, cólon, próstata, bexiga e cabeça e pescoço. Na glândula tireoide esse risco aumenta em 2,6 vezes ${ }^{1,5,6,8,12,13}$. Sendo o GST um fator de proteção do DNA da célula, os pacientes com genótipo nulo para esse sistema não possuem essa proteção e, consequentemente, estão mais propensos ao desenvolvimento de diversos tumores ${ }^{5-8,12-19}$. As células cancerosas possuem habilidade de superexpressar determinados genes a fim de adquirir qualidades que permitam sua multiplicação descontrolada. Os genes que codificam o GTS poderiam estar superexpressos nas células cancerosas do carcinoma papilífero de tireoide, conferindo uma proteção contra a morte celular desse tumor. Os pacientes com genótipo negativo para ambos os genes não possuem essa proteção na célula maligna e, por isso, poderiam estar relacionados com um pior prognóstico.

Quanto a relacionar o prognóstico com recidiva ou mortalidade, isto é muito difícil devido ao comportamento biológico indolente do carcinoma papilífero da tireoide. A literatura recomenda seguimento de trinta anos para obtenção de resultados concludentes sobre recidiva e mortalidade, porém não avaliam prognóstico com essas variáveis, exatamente pela dificuldade em se acompanhar um número significativo de pacientes durante este período. Por este motivo existem varias classificações tentando estabelecer o prognóstico baseado em achados clínicos e histopatológicos. Assim, a classificação AMES; AGES (substitui "Metastasis" por "Grade" - grau de diferenciação); MACIS ("Metastasis", "Age", "Complete Tiroidectomy", "Invasion", "Size") e outras dividem os doentes em alto e baixo risco de mortalidade.

Sendo assim, nosso objetivo é achar um fator molecular, o sistema GTS, que pudesse estabelecer, de modo objetivo se o paciente está no grupo de alto ou baixo risco, podendo indicar tratamentos mais ou menos agressivos de acordo com o grupo de risco do paciente.

\section{Objetivo}

Verificar se a prevalência dos fatores genotípicos nulos dos genes (GSTT1 e GSTM1) que codificam as enzimas das famílias "mu e theta" do sistema Glutationa-S-Transferase (GST) são adequadas para avaliar o risco de melhor ou pior prognóstico do carcinoma papilífero da tireoide.

\section{Métodos}

Estudo prospectivo Iongitudinal realizado pela Disciplina de Cirurgia de Cabeça e Pescoço da Faculdade de Ciências Médicas da Santa Casa de São Paulo (FCMSCSP) em colaboração com - laboratório de Genética Molecular do Câncer (GEMOCA) da UNICAMP.

Foram analisados 66 pacientes com carcinoma papilífero de tireoide com média de idade de 44 anos (entre 16 e 72 anos), sendo 53 pacientes $(80,3 \%)$ do sexo feminino e $13(19,7 \%)$ do sexo masculino. Para definirmos quais pacientes de baixo e alto risco de mortalidade para carcinoma papilifero da tireoide utilizamos o sistema AMES, constituindo-se dois grupos. O grupo A com 17 (27\%) pacientes com alto risco de mortalidade e 0 grupo B com 49 (73\%) de baixo risco.

As amostras de tecido tireoidiano foram coletadas durante o ato cirúrgico. Foi ressecado um espécime central e livre de necrose do nódulo suspeito na glândula tireoide. Essa amostra foi dividida em duas outras, a primeira foi enviada para exame anatomopatológico e a segunda foi colocada em criotubos imediatamente imersos em nitrogênio líquido. As amostras permaneceram armazenadas em freezer a $-80^{\circ} \mathrm{C}$ até o momento de seu processamento. 0 diagnóstico foi comprovado por meio do laudo anatomopatológico.

Todos os pacientes desse estudo foram devidamente informados que participavam da presente investigação e assinaram - Termo de Consentimento Livre e Esclarecido, conforme as determinações do Comitê de Ética em Pesquisa.

\section{Método de extracão de DNA de tecido a fresco:}

Do material coletado a fresco, foram macerados $50 \mathrm{mg}$ de tecido ainda congelado e o DNA foi extraído utilizando-se o método do Fenol/Clorofórmio. Os tecidos foram digeridos com Proteinase $\mathrm{K}$ e tampão de Proteinase $\mathrm{K}$ e incubados a $55^{\circ} \mathrm{C}$ durante 16 horas.

Os genes GSTM1 e GSTT1 foram amplificados por reação em cadeia de polimerase (PCR) utilizando-se o termociclador da marca Perkin Elmer. A sequência do primer utilizado foi 5'CTGCCCTACTTGATTGATGGG3' (fita sense) e 5'CTGGATTGTAGCAGATCATGC3' (fita antisense) para o GSTM1 e amplificou um produto de $273 \mathrm{pb}$. Para o gene GSTM1 foi utilizado o primer 5'TTCCTTACTGGTCCTCACATCTC3' (fita sense) e 5'TCACCGGATCATGGCCAGCA3' (fita antisense) que resultou na amplificação de um produto de $480 \mathrm{pb}$. 0 gene da $\beta$-globina foi utilizado como controle positivo das amostras de $\mathrm{DNA}^{17}$ e o primer utilizado foi 5'ATACAATGTATCATGCCTCTTTGCACC3' resultando em um produto de $630 \mathrm{pb}$. Os três pares de primers foram incluídos na mesma reação caracterizando assim uma PCR-multiplex ${ }^{20}$. A PCR-multiplex foi otimizada para detectar a presença ou ausência dos genes GSTM1 e GSTT1 incluindo o gene $\beta$-globina como controle da integridade do DNA de nossas amostras. O processo de amplificação iniciou-se com a desnaturação da cadeia de DNA a $94^{\circ} \mathrm{C}$ por 2 minutos, seguidos de 35 ciclos de duração de 1 minuto cada a $95^{\circ} \mathrm{C}$, a $62^{\circ} \mathrm{C}$ e a $72^{\circ} \mathrm{C}$, finalizando com 1 ciclo de 7 minutos a $72^{\circ} \mathrm{C}$.

Os produtos obtidos na reação de amplificação por PCR foram submetidos a gradiente eletroforético em gel de agarose a $2 \%$.

Alíquotas de $8 \mu \mathrm{l}$ de cada reação de PCR foram misturadas com $2 \mu$ lde azul de bromofenol e visualizadas sob iluminação ultravioleta. Foi utilizado um marcador de 100 pb para a calibração da reação. Foram considerados genótipos nulos para GSTM1, os casos em que estava ausente o produto de 273 pb, para GSTT1, ausência do produto de 480 pb. A ausência de bandas em GSTT1 e GSTM1 quando o gene $\beta$-globina está claramente presente identifica os genótipos nulos para estes dois alelos. 
Visualizamos os resultados da amplificação excitando o corante incorporado ao DNA (brometo de etídeo) com luz ultravioleta em um sistema Kodak de visualização e fotografia.

Os resultados obtidos foram submetidos ao teste do Qui quadrado para verificar sua significância estatística, considerando-se 5\% como valor significativo.

\section{Resultados}

A análise do grupo de pacientes mostrou que o gene GSTT1 estava presente em 55 pacientes (83,3\%) e ausente em 11 $(16,7 \%)$. Já o gene GSTM1 esteve presente em $36(45,5 \%)$ e ausente em 30 pacientes (54,5\%).

Quatro pacientes $(6,1 \%)$ apresentavam genótipo negativo para os genes GSTT1 e GSTM1, 29 (43,9\%) apresentavam genótipo positivo para ambos os genes estudados; 26 pacientes $(39,4 \%)$ apresentavam o gene GSTT1, porém não possuíam o gene GSTM1 e sete outros $(10,6 \%)$ eram positivos para GSTM1 e negativos para GSTT1 (Tabela 1 ).

Dos 17 pacientes que apresentaram alto risco (grupo A): um possuía a deleção de ambos os genes estudados, dois possuíam GSTM1 presente e a deleção de GSTT1, oito possuíam o gene GSTM1 deletado e o gene GSTT1 presente e seis possuíam ambos os genes presentes.

Dos 49 pacientes que apresentaram baixo risco (grupo B): três apresentam genótipo nulo para ambos os genes estudados; cinco apresentam GSTM1, mas não GSTT1, 18 apresentam GSTT1, mas não GSTM1 e 23 apresentam os dois genes (Tabela 2).

\section{Discussão}

A maioria dos pacientes foi considerada de baixo risco de mortalidade de acordo com o índice AMES. Isto se deve ao advento de novas tecnologias que possibilitam o diagnóstico precoce e o tratamento adequado com mínimas sequelas e principalmente ao próprio comportamento biológico do carcinoma papilífero ${ }^{21}$.

Os genes que codificam as proteínas do GST são conhecidos pelo seu polimorfismo na população geral e tendem a variar com a etnia ${ }^{15,22,23}$, por isso o fato de haver porcentagem maior de pessoas que possuem o gene GSTT1 $(83,3 \%)$ em relação ao gene GSTM1 (54,5\%) não é um dado estatisticamente significativo. Os dados da literatura são inconclusivos a respeito da hipótese de haver maior importância do gene GSTT1 ou do gene GSTM1 no processo de carcinogênese, de modo que não se pode prever o risco de morte para os pacientes que apresentem genótipo nulo para GSTT1 e positivo para GSTM1 ou vice e versa.

Analisando as frequências dos genes estudados, podemos observar que a minoria dos pacientes com carcinoma papilífero da tireoide possuía o genótipo negativo para ambos os genes $(6,1 \%)$. Sabe-se que a ausência desses dois genes está implicada no maior risco para desenvolvimento de câncer de tireoide, principalmente do carcinoma papilífero de tireoide ${ }^{14,17-20}$ Quando comparamos nossos resultados com a literatura nacional, observamos que houve uma menor frequência desse genótipo em nossa amostra. Morari et al. ${ }^{19}$. (2002) encontraram uma frequência de $10 \%$ do genótipo duplo negativo entre os pacientes com carcinoma papilífero da tireoide. Isso pode estar ocorrendo devido ao pequeno número de amostras em nosso
Tabela 1 - Distribuição dos pacientes segundo as possibilidades genotípicas quanto aos genes GSTT1 e GSTM1

\begin{tabular}{lccc}
\hline \multicolumn{2}{c}{ Genótipo } & Frequência & Porcentagem \\
\hline$[\mathrm{T}-]$ & {$[\mathrm{M}-]$} & 4 & $6.1 \%$ \\
{$[\mathrm{~T}-]$} & {$[\mathrm{M}]$} & 7 & $10.6 \%$ \\
{$[\mathrm{~T}]$} & {$[\mathrm{M}-]$} & 26 & $39.4 \%$ \\
[T ] & [M ] & 29 & $43.9 \%$ \\
Total & & 66 & $100.0 \%$ \\
\hline
\end{tabular}

T-] = gene GSTT1 ausente

[T ] = gene GSTT1 presente

$[\mathrm{M}-\mathrm{]}=$ gene GSTM 1 ausente

$[\mathrm{M}]$ = gene GSTM1 presente

\begin{tabular}{|c|c|c|c|c|c|}
\hline \multicolumn{6}{|c|}{ Genótipo } \\
\hline AMES & [T-] / [M-] & {$[\mathrm{T}-] /[\mathrm{M}]$} & {$[\mathrm{T}] /[\mathrm{M}-]$} & {$[\mathrm{T}] /[\mathrm{M}]$} & Total \\
\hline $\begin{array}{l}\text { Grupo } \mathrm{A} \\
\text { (alto risco) }\end{array}$ & 1 & 2 & 8 & 6 & 17 \\
\hline $\begin{array}{l}\text { Grupo B } \\
\text { (baixo risco) }\end{array}$ & 3 & 5 & 18 & 23 & 49 \\
\hline $\begin{array}{l}\text { Total } \\
p=0,85873\end{array}$ & $5^{4}$ & 7 & 26 & 29 & 66 \\
\hline
\end{tabular}

-] / [M-] = gene GSTT1 ausente e gene GSTM1 ausente

[T-] / [M ] = gene GSTT1 ausente e gene GSTM1 presente

[T ] / [M-] = gene GSTT1 presente e gene GSTM1 ausente

$[\mathbf{T}] /[\mathbf{M}]=$ gene GSTT1 presente e gene GSTM1 presente

estudo. Observamos também que a maioria desses pacientes encontra-se no grupo de baixo risco (75\%). Isso poderia estar confirmando a hipótese do GST ausente ser um fator de melhor prognóstico, pois o GST confere proteção tanto a célula normal como para a neoplásica, e por isso poderia estar relacionado com uma maior agressividade tumoral. No entanto devemos levar em consideração o fato de que o carcinoma papilífero de tireoide apresenta em geral boa evolução clinica, portanto espera-se que haja uma maior frequência de pacientes considerados de baixo risco, independentemente de suas características genéticas ${ }^{24}$.

Rigual et al. (2005) estudaram 33 pacientes com carcinoma papilífero da tireoide e encontraram uma associação positiva entre a deleção do gene GSTM1 e o risco de recidiva e mortalidade da doença, avaliado pelo sistema GAMES (Memorial Sloan-Kettering $)^{25}$.

No nosso estudo 43,9\% dos pacientes apresentaram genótipo positivo para ambos os genes, corroborando os dados publicados em 2002, por Morari et al. que encontraram uma frequência de $40 \%$ desse genótipo no grupo de pacientes com carcinoma papilífero ${ }^{19,25}$.

Quanto ao prognóstico, diferentemente do esperado, a maioria dos pacientes com genótipo duplo positivo (GSTT1 presente e GSTM1 presente) foi classificado como baixo risco pelo índice AMES. Esperava-se que esses pacientes tivessem uma pior evolução clínica, devido à presença do GTS que poderia estar agindo como um fator protetor contra a morte das células neoplásicas. A princípio esse resultado parece demonstrar que 
Gonçalves AJ ET AL.

o GST não está implicado no prognóstico do câncer de tireoide, no entanto, devemos considerar o fato de que a presença desses genes não implica necessariamente no funcionamento do GST. Os genes poderiam não estar sendo expressos e, portanto o fenótipo desses indivíduos seria semelhante ao dos pacientes com genótipo duplo negativo, isso explicaria a alta frequência de pacientes com genótipo duplo positivo classificados como baixo risco pelo índice AMES.

Esse estudo correlacionou os fatores prognósticos avaliados pelo sistema AMES com as características genéticas dos pacientes estudados, tentando estabelecer uma relação entre o GST e a evolução clínica dos pacientes com câncer de tireoide. No entanto, quer seja pelos motivos anteriormente citados, ou pelas próprias limitações do sistema AMES, não foi possível estabelecer essa relação.

\section{Conclusão}

Concluímos que não podemos estabelecer relação entre os genes estudados com o prognóstico do câncer de tireoide analisados pelo sistema AMES.

\section{Conflito de interesse: não há}

\section{SUMmARY}

\section{GST GENES EXPRESSION AS PROGNOSTIC FACTOR IN PAPILLARY THYROID} CANCER

PURPOSES. Analyze the relationship between the AMES classification and molecular factors from Glutation-S-Transferase System, specifically the GSTT1 and GSTM1 in patients with well differentiated thyroid cancer.

Methods. Samples of thyroid tissue of 66 patients with papillary thyroid carcinoma were obtained (53 women and 13 men). Patients were divided in two groups (high and low risk) according to the AMES classification. In each group, presence of the null genotype of both GST enzymes system was studied. These results were compared with the AMES classification. Samples were obtained in the operating room immediately after thyroidectomy, placed in cryotubes, immersed in liquid nitrogen and stored in a freezer at $-80^{\circ} \mathrm{C}$. DNA of this enzymes was extracted by the fenol-cloroformium method.

RESULTS. There were 17 high risk patients and 49 low risk patients. The null genotype of the high risk group was $5.8 \%$ and in the other group was $6.1 \%$.

CONCLUSION. There was no relationship between absence of genes GSTT1 and GSTM 1 and prognosis of the papillary thyroid carcinoma when compared to the AMES classifications. [Rev Assoc Med Bras 2009; 55(3): 279-82]

KEYwordS: Glutatione S-Transferase. Thyroid Carcinoma., Prognoses.

\section{REFERÊNCIAS}

1. Haq M, Harmer C. Thyroid cancer: an overview. Nucl Med Commun. 2004;25 (9):861-7.

2. Kushchayeva Y, Duh QY, Kebebew E, Clark $\mathrm{OH}$. Prognostic indications for Hurthle cell cancer. World J Surg. 2004;28(12):1266-70.

3. Thompson GB, Hay ID. Current strategies for surgical management and adjuvant treatment of childhood papillary thyroid carcinoma. World J Surg. 2004:28(12): 1187-98.
4. Cady B, Rossi R. An expanded view of risk group definition in differentiated thyroid carcinoma. Surgery. 1998;104(6):947-53.

5. Ntais C, Polycarpou A, loannidis JP. Association of GSTM 1, GSTT1, and GSTP1 gene polymorphisms with the risk of prostate cancer: a meta-analysis. Cancer Epidemiol Biomarkers Prev. 2005;14(1):176-81.

6. Srivastava DS, Mandhani A, Mittal B, Mittal RD. Genetic polymorphism of glutathione S-transferase genes (GSTM1, GSTT1 and GSTP1) and susceptibility to prostate cancer in Northern India. BJU Int. 2005;95(1):170-3.

7. Ueda M, Hung YC, Terai Y, Kanda K, Takehara M, Yamashita H, et al. Glutathione S-transferase GSTM1, GSTT1 and p53 codon 72 polymorphisms in human tumor cells. Hum Cell. 2003;16(4):241-51.

8. Habdous M, Siest G, Herbeth B, Vincent-Viry M, Visvikis S. [Glutathione S-transferases genetic polymorphisms and human diseases: overview of epidemiological studies] Ann Biol Clin (Paris). 2004;62(1):15-24.

9. British Thyroid Association. Guidelines for the managements of thyroid cancer in adults. London: Royal College of Physicians; 2002.

10. Leenhardt L, Grosclaude P, Cherie-Challine L. Thyroid Cancer Committee. Increased incidence of thyroid carcinoma in France: a true epidemic or thyroid nodule management effects? Report from the French Thyroid Cancer Committee. Thyroid. 2004;14(12):1056-60.

11. Sriram U, Patacsil LM. Thyroid nodules. Dis Mon. 2004;50(9):486-526.

12. Jhavar SG, Sarin R, Chopra S, Kotnis A, Mulherkar R, Ahern R, et al. Females with paired occurrence of cancers in the UADT and genital region have a higher frequency of either Glutathione S-transferase M1/T1 null genotype. J Carcinog. 2005;4(1):6.

13. Sobti RC, Al-Badran Al, Sharma S, Sharma SK, Krishan A, Mohan H. Genetic polymorphisms of CYP2D6, GSTM1, and GSTT1 genes and bladder cancer risk in North India. Cancer Genet Cytogenet. 2005;156(1):68-73.

14. Gaspar J, Rodrigues S, Gil OM, Manita I, Ferreira TC, Limbert E, et al. Combined effects of glutathione S-transferase polymorphisms and thyroid cancer risk. Cancer Genet Cytogenet. 2004;151(1):60-7.

15. Hayes JD, Pulford DJ. The Glutathione S-transferase supergene family. Regulation of GST and the contribution of the isoenzymes to cancer chemoprotection and drug resistance. Crit Rev Biochem Mol Biol. 1995;30(6):445-600.

16. Granja F, Morari EC, Assumpcao LV, Ward LS. GSTO polymorphism analysis in thyroid nodules suggest that GSTO1 variants do not influence the risk for malignancy. Eur J Cancer Prev. 2005;14(3) 277-80.

17. Ward LS, Assumpcao LV. Thyroid cancer: prognostic factors and treatment. Arq Bras Endocrinol Metabol. 2004;48(1):126-36.

18. Granja F, Morari J, Morari EC, Correa LA, Assumpcao LV, Ward LS. GST profiling may be useful in the screening for thyroid nodule malignancy. Cancer Lett. 2004;209(2):129-37.

19. Morari EC, Leite JL, Granja F, Assumpcao LV, Ward LS. The null genotype of glutathione s-transferase M1 and T1 locus increases the risk for thyroid cancer. Cancer Epidemiol Biomarkers Prev. 2002;11(11):1485-8.

20. Arruda VR, Grignolli CE, Gonçalves MS, Soares MC, Menezes R, Saad ST, et al. Prevalence of the homozygous for the deleted alleles of glutathione S-transferase Mu (GSTMI) and theta (GSTM1) among distinct ethnic groups from Brazil: relevance to environmental carcinogenesis? Clin Genetics. 1998:54(3):210-4

21. Noguchi S, Katev N, Miwa K. Therapeutic strategies and long - term results in differentiated thyroid cancer. J Surg Oncol. 1998;67(1):52-9.

22. Seidegard J, Vorachek WR, Pero RW, Pearson WR. Hereditary differences in the expression of human glutathione transferase active on trans-stilbene oxide are due to a gene deletion. Proc Natl Acad Sci USA. 1998;85(19):7293-7.

23. Pemble S, Schroerder KR, Spencer SR, Meyer DJ, Hailler E, Bolt HM, et al. Human glutathione S-transferase theta (GSTT1): cDNA cloning and the characterization of a genetic polymorphism. Biochem J. 1994;300(2):271-6.

24. Ho, T., C. Zhao, Liu A, Wei Q, Sturgis EM. Glutathione S-transferase polymorphisms and risk of differentiated thyroid carcinomas: a case-control analysis. Arch Otolaryngol Head Neck Surg. 2006;132(7):756-61.

25. Rigual NR, Anderson GR, Wiseman S, Alrawi S, Stoler DL. Molecular prognosticators and genomic instability in papillary thyroid cancer. Laryngoscope. 2005;115(8):1479-85.

Artigo recebido: 29/11/07

Aceito para publicação: 30/07/08 